\title{
Visual impairment and blindness in students of a school for the blind in Queretaro, Mexico: A causal assessment
}

\section{Discapacidad visual y ceguera entre los estudiantes de una escuela para ciegos en Querétaro, México: Una evaluación causal}

\author{
Rocío Escárcega-Servín ${ }^{1}$, J. Fernando Pérez-Pérez ${ }^{1 *}$, Van Charles Lansingh ${ }^{1,2}$ and Ellery M. Lopez-Star ${ }^{1}$ \\ ${ }^{1}$ Instituto Mexicano de Oftalmología IAP, Queretaro, Mexico; ${ }^{2} \mathrm{Help}$ Me See, New York, United States
}

\begin{abstract}
Objective: To describe the causes of blindness in the students of the school for blind children "Josefa Vergara" in Queretaro, Mexico; as well as identifying treatable causes in the studied population. Methodology: The study was conducted in the period from December 2017 to February 2018, at the Josefa Vergara School for Children with Blindness in Queretaro, Mexico. Thirty students participated. The participants were interviewed and examined by the authors. The results obtained in the study were analyzed with the SPSSTM software version 21. Results: The majority of participants were blind $28(93 \%)$. The most frequent causes of visual loss were retinopathy of prematurity in 11 participants $(36.7 \%)$ and congenital cataract in 5 participants (16.6\%). In a lower percentage, Leber's congenital amaurosis was found in 2 participants (6.7\%), congenital retinal detachment in 2 participants (6.7\%), retinoblastoma in 2 participants (6.7\%), optic nerve hypoplasia in 2 participants (6.7\%), among others. $73 \%$ of the participants in the study had a treatable cause of blindness. Conclusions: The retina was the main anatomical site affected. The most common diagnosis was sequelae of retinopathy of prematurity. Most participants had treatment alternatives that could prevent blindness in early stages of their disease. It is necessary to implement and intensify measures in the Mexican health system for the prevention of blindness in the pediatric population.
\end{abstract}

Key words: Blindness. Pediatric. School. Mexico. Incidence. Prevention.

\section{Resumen}

Objetivo: Describir las causas de ceguera en los alumnos de la escuela para niños ciegos Josefa Vergara en Querétaro, México; así como identificar causas tratables en la población estudiada. Metodología: El estudio se llevó a cabo en el periodo de diciembre de 2017 a febrero de 2018 en la escuela para niños ciegos Josefa Vergara de Querétaro, México. Participaron 30 estudiantes. Los pacientes fueron entrevistados y examinados por los autores. Los resultados obtenidos con el estudio fueron analizados con el programa SPSSMR versión 21. Resultados: La mayoría de los sujetos eran ciegos $(28,93 \%)$. Las causas más frecuentes de pérdida visual fueron retinopatía del prematuro en 11 pacientes $(36.7 \%)$ y catarata congénita en 5 pacientes (16.6\%). En menor porcentaje se encontró amaurosis congénita de Leber, en 2 pacientes (6.7\%), desprendimiento de retina congénito, en 2 pacientes (6.7\%), retinoblastoma, en 2 pacientes (6.7\%), hipoplasia del

Correspondence:

*Fernando Pérez-Pérez

Avenida Estadio, $\mathrm{s} / \mathrm{n}$

Colinas de Cimatario, Centro Sur Date of reception: 16-10-2018

C.P. 76090, Santiago de Querétaro, Qro, México Date of acceptance: 01-04-2019

E-mail: fernando.perez@imoiap.edu.mx

DOI: 10.24875/RMOE.M19000073
Available online: XX-XX-2019 Rev Mex Oftalmol(Eng).2019;93(4):144-149

www.rmo.com.mx 2604-1731/@ 2019 Sociedad Mexicana de Oftalmología. Published by Permanyer México SA de CV. This is an Open Access article under the CC BY-NC-ND license (http://creativecommons.org/licenses/by-nc-nd/4.0/). 
nervio óptico, en 2 pacientes (6.7\%), entre otras. El 73\% de los participantes en el estudio tenían una causa tratable de ceguera. Conclusiones: La retina fue el principal sitio anatómico afectado. El diagnóstico más común fue secuelas de retinopatía del prematuro. La mayoría de los pacientes tenían alternativas de tratamiento que habrían podido evitar la ceguera en estadios tempranos de su enfermedad. Es necesario implementar y reforzar medidas en el sistema de salud mexicano para la prevención de ceguera en la población pediátrica.

Palabras clave: Ceguera. Infantil. Escuela. México. Incidencia. Prevención.

\section{Introduction}

Worldwide, the estimated number of children with visual impairment is 19 million, of which 12 million have uncorrected refractive errors. Approximately 1.4 million suffer irreversible blindness and need visual rehabilitation services ${ }^{1}$. The prevalence is related to the socioeconomic development of the country, as well as to the mortality rate in children under 5 years of age.

The results of population-based studies indicate a lower prevalence of blindness in children than in adults, approximately $0.2-0.3$ per 1,000 children in industrialized countries and 1 to $1-1.5$ per 1,000 children in developing countries ${ }^{2}$, where up to $75 \%$ of the causes of blindness in children are preventable or treatable ${ }^{3}$.

Epidemiological data on the prevalence of blindness in children, as well as the main causes, are important in terms of establishing prevention and control programs. However, the different types of alterations resulting in blindness vary in incidence and prevalence between regions and countries.

The main causes of childhood blindness can be identified analyzing schools for the visually impaired or through estimates of health indicators, for example, childhood mortality rate. Due to the low prevalence of childhood blindness in the general population, it is difficult to conduct population-based studies, since a large sample size is required to have reliable statistical results.

There are multiple reports ${ }^{4-6}$ of the causes of blindness in children in different countries of Latin America, as a result of studies carried out in identifiable groups of affected children, that is, in schools for children with blindness. The most recent of these, performed in Guadalajara, Mexico, in 2011, reported retinopathy of prematurity as the main cause of blindness, with a percentage of $34.7 \%{ }^{4}$.

Epidemiological studies report corneal opacity as the most common cause of childhood blindness in countries with a high childhood mortality rate, such as Bolivia, the Dominican Republic and Peru, where approximately $20 \%$ of causes are attributed to corneal opacity. In contrast to countries such as USA, Chile and Argentina that report very few cases ${ }^{5,6}$.
Retinopathy of prematurity is an important cause of blindness in countries with an intermediate childhood mortality, where the survival rate of low birth weight newborns has increased, but the neonatal care guidelines are inadequate. Such is the case of countries like Cuba, Mexico and Paraguay, where it represents 30\% of the causes of blindness. In contrast, the United States had a prevalence of $8 \%$, probably as a result of adequate neonatal intensive care. Likewise, Bolivia, the Dominican Republic and Peru report retinopathy of prematurity as a rare cause, possibly due to the low survival rate of premature infants ${ }^{5,6}$.

Cataract shows a homogenous prevalence among the different regions and is one of the leading causes of blindness reported in the literature. Cataracts may be congenital or acquired, related to rubella or to genetic diseases ${ }^{5,6}$.

The program of the World Health Organization for the prevention of blindness and the International Centre for Eye Health developed a standardized methodology to report the causes of visual loss in children, with special emphasis on the identification of preventable or treatable causes ${ }^{7}$.

The anatomical classification of the causes of visual loss defines the part of the eye that is affected and that causes the greatest visual loss. When two or more anatomical sites are involved, the largest one is selected, and if the contribution is equal, the most treatable condition is selected. The etiological classification is divided into five categories, according to the time of onset of the condition that led to blindness (hereditary, intrauterine, perinatal, during childhood and unknown) ${ }^{7}$.

The World Health Organization International Classification of Diseases defines severe visual impairment as a best-corrected visual acuity of less than 20/200 but better than 10/200 in the best eye and blindness as a visual acuity worse than $20 / 400$ in the best eye. It is important to distinguish these categories, because people with visual disability, unlike those with blindness, still have a certain degree of vision used in activities for daily living ${ }^{8}$. 
Childhood blindness represents a problem in terms of morbidity, economic loss and social burden, since it affects the years of productive working age. In contrast to adults, who generally become blind in their later years, with less social impact.

Mexico has a population of more than 120 million, is ranked $56^{\text {th }}$ in the United Nations Development Program and is classified as a country with a high level of development. In 2015, life expectancy was 76.92 years and $98 \%$ of children were enrolled in a primary education program. Queretaro is one of the 32 states of Mexico and has a population of $2,038,372$ people, of whom 545,065 are children $(30 \% \text { of the population })^{9}$. The childhood mortality rate in Queretaro is 14 per 1,000 births, according to the National Institute of Statistics, Geography and Informatics (INEGI) in 2011. Both indices suggest that the prevalence of blindness in children is low and that retinopathy of prematurity may be an important cause; however, there is little information on the causes of childhood blindness in Mexico.

The prevention of blindness due to retinopathy of prematurity requires quality neonatal care, as well as programs that guarantee timely detection. The guidelines for prevention, detection and treatment of retinopathy of prematurity were published in Mexico in 2007 but have not been widely implemented.

\section{Objective}

To describe the causes of blindness in the students of the Josefa Vergara School for Children with Blindness in Queretaro, Mexico, as well as identify treatable causes in the studied population.

\section{Methodology}

The study was designed to determine the causes of blindness in the students of the school for blind children in Queretaro, Mexico, as well as to identify treatable causes in the studied population.

This study took place from December 2017 through February 2018 at the Josefa Vergara School for Children with Blindness in Queretaro, Mexico. The thirty students enrolled in this school participated, with an age range of 4 to 18 years. School authorities approved the study, and parents or guardians signed an informed consent form. The Instituto Mexicano de Oftalmología Ethics and Research Committee approved this study. The participants and their parents were interviewed by the authors.

All students were examined by a group of ophthalmologists and a pediatric ophthalmologist. Information was obtained regarding previous ophthalmological and systemic diagnoses, surgeries and treatments, assessment of previous diagnostic tests, visual acuity at the time of the study, refractive measurement if necessary and ophthalmological exploration.

We followed the clinical protocol for the measurement of distance visual acuity in patients with low vision proposed by the American Academy of Ophthalmology. This protocol states that if the patient cannot distinguish the optotype at the predetermined distance, the chart is progressively approached until visual acuity can be measured. The Snellen and illiterate "E" charts were used. In participants who showed visual acuity improvement with pinhole or those who had a visual acuity better than light perception without significant anatomical deficit, refraction was performed with retinoscopy.

Regarding ophthalmological exploration, the anterior segment was examined with a portable slit lamp and posterior segment was explored using direct ophthalmoscopy. In participants who required it, pharmacological dilatation and fundus exploration with indirect ophthalmoscope and $20 \mathrm{D}$ and $28 \mathrm{D}$ lenses was performed.

We followed the guidelines for reporting causes of visual loss of the program for the prevention of blindness of the World Health Organization and those of the International Centre for Eye Health ${ }^{8}$. After capturing all the abnormalities in each eye, an anatomical site was chosen as the main cause of blindness. The underlying etiology was determined where possible and categorized according to the time of onset of the condition.

In terms of visual prognosis, we used the ranges of visual acuity proposed by the World Health Organization and the International Classification of Diseases, ICD-10. Good visual prognosis was defined as reaching a best-corrected visual acuity of 20/60 in the best eye. Moderate visual prognosis was defined as a best-corrected visual acuity from $20 / 80$ to $20 / 200$, and poor prognosis was defined as a best-corrected visual acuity worse than $20 / 200$ in the best eye.

All participants were referred to the ophthalmological center Instituto Mexicano de Oftalmología (Private Assistance Institute, IAP) to open their medical records and receive follow-up of their ophthalmological condition. Some of them needed additional tests and assessments, in order to determine the etiology or provide treatment. The results obtained were collected, processed and analyzed with the statistical software SPSS ${ }^{\circledR}$ version 21 .

\section{Results}

We examined 30 participants from the Josefa Vergara School for Chldren with Blindness in Queretaro, 
Table 1. Age

\begin{tabular}{|l|c|c|}
\hline Age (years) & Frequency & Percentage \\
\hline 4 & 1 & $3.3 \%$ \\
\hline 5 & 2 & $6.7 \%$ \\
7 & 4 & $13.3 \%$ \\
8 & 3 & $10.0 \%$ \\
9 & 3 & $10.0 \%$ \\
10 & 5 & $16.7 \%$ \\
11 & 2 & $6.7 \%$ \\
12 & 4 & $13.3 \%$ \\
13 & 1 & $3.3 \%$ \\
14 & 1 & $3.3 \%$ \\
16 & 2 & $6.7 \%$ \\
18 & 2 & $6.7 \%$ \\
\hline Total & 30 & $100 \%$ \\
\hline
\end{tabular}

Table 2. Main cause of visual loss

\begin{tabular}{|l|c|c|}
\hline Diagnosis & Frequency & Percentage \\
\hline ROP & 11 & $36.7 \%$ \\
Congenital cataract & 5 & $16.6 \%$ \\
Leber's congenital amaurosis & 2 & $6.7 \%$ \\
Optic nerve hypoplasia & 2 & $6.7 \%$ \\
Retinoblastoma & 2 & $6.7 \%$ \\
Congenital retinal detachment & 2 & $6.7 \%$ \\
Glaucoma secondary to aniridia & 1 & $3.3 \%$ \\
Unspecified retinal dystrophy & 1 & $3.3 \%$ \\
Ectopia lentis & 1 & $3.3 \%$ \\
Ametropia & 1 & $3.3 \%$ \\
Corneal leucoma & 1 & $3.3 \%$ \\
Optic nerve atrophy & 1 & $3.3 \%$ \\
\end{tabular}

Mexico. Participants had an age range of 4 to 18 years (Table 1), with 20 female (66.7\%) and 10 male (33.3\%). Most participants were blind (28 [93\%]) and 2 (7\%) had low vision. Fourteen $(46.6 \%)$ of the legally blind participants presented a visual acuity of no light perception, $2(7 \%)$ of light perception, $6(20 \%)$ of hands motion, $4(13 \%)$ of counting fingers to one meter, and $2(7 \%)$ of $20 / 200$. Most participants had no history of eye surgery (26 [86.7\%]), while $4(13.3 \%)$ had eye surgery history.

The most frequent causes of visual loss were sequelae of retinopathy of prematurity in 11 participants $(36.7 \%)$ and congenital cataract in 5 participants (16.6\%). Other causes were Leber's congenital amaurosis in 2 participants $(6.7 \%)$, congenital retinal detachment in 2 participants $(6.7 \%)$, retinoblastoma in 2 participants $(6.7 \%)$, optic nerve hypoplasia in 2 participants $(6.7 \%)$, among others (Table 2). Regarding the associated systemic factors, we found TORCH and Marfan syndrome in one patient each, as well as a case of resected subependymal giant cell astrocytoma (Table 3).

The retina was the main anatomical site of visual loss $(60 \%)$ as detailed in Table 4 , followed by the lens, the
Table 3. Systemic correlations and findings

\begin{tabular}{|l|l|l|}
\hline Disorder & Frequency & Ocular findings \\
\hline TORCH & 1 & $\begin{array}{l}\text { OD: total cataract } \\
\text { OS: salt and } \\
\text { pepper fundus, } \\
\text { optic nerve } \\
\text { hypoplasia }\end{array}$ \\
\hline Marfan syndrome & 1 & $\begin{array}{l}\text { OD: ectopia lentis } \\
\text { OS: postoperative } \\
\text { aphakia }\end{array}$ \\
\hline $\begin{array}{l}\text { Resected subependymal } \\
\text { giant cell astrocytoma }\end{array}$ & 1 & $\begin{array}{l}\text { Both eyes: optic } \\
\text { nerve atrophy }\end{array}$ \\
\hline
\end{tabular}

Table 4. Anatomic site causing the visual loss

\begin{tabular}{|l|c|c|}
\hline Anatomic site & Frequency & Percentage \\
\hline Retina & 18 & $60 \%$ \\
\hline Lens & 6 & $20 \%$ \\
\hline Optic nerve & 4 & $13.3 \%$ \\
\hline Cornea & 1 & $3.3 \%$ \\
\hline Eyeball & 1 & $3.3 \%$ \\
\hline
\end{tabular}

Table 5. Etiology of blindness and visual impairment

\begin{tabular}{|l|c|c|}
\hline Etiology & Frequency & Percentage \\
\hline Hereditary & 4 & $13.3 \%$ \\
\hline Intrauterine & 11 & $36.7 \%$ \\
\hline Perinatal & 11 & $36.7 \%$ \\
\hline Childhood & 2 & $6.7 \%$ \\
\hline Unknown & 2 & $6.7 \%$ \\
\hline
\end{tabular}

optic nerve and, to a lesser extent, the cornea and the entire eyeball, with $3.3 \%$ each.

Regarding the etiological factors (Table 5), intrauterine and perinatal factors were found in first place, with $36.7 \%$ each. Childhood factors were observed in a lower percentage, and in $6.7 \%$ of the participants, etiology was unknown.

Seventy-three percent of the study participants had a cause of blindness that could be treatable or even preventable in early stages of the disease. Regarding the prognosis of visual recovery, most participants, 28 (93\%), had a poor prognosis, and 2 participants (6.7\%) had a moderate prognosis of visual acuity recovery. None of the individuals had a good visual prognosis.

The results of this study show different causes of blindness originating in each of the ocular anatomical 
Table 6. Nystagmus

\begin{tabular}{|l|c|c|}
\hline & Frequency & Percentage \\
\hline No & 17 & $56.7 \%$ \\
\hline Yes & 13 & $43.3 \%$ \\
\hline Total & 30 & $100.0 \%$ \\
\hline
\end{tabular}

Table 7. Strabismus

\begin{tabular}{|l|c|c|}
\hline & Frequency & Percentage \\
\hline No & 22 & $73.3 \%$ \\
\hline Yes & 8 & $26.7 \%$ \\
\hline Total & 30 & $100.0 \%$ \\
\hline
\end{tabular}

sites and with multiple associated alterations. Nystagmus was observed in 13 participants (43.3\%), and 8 (26.7\%) also had strabismus (Tables 6 and 7 ).

\section{Discussion}

Most of the previous studies that examined children in schools for the blind, report comparable results. The proportion of children with significant visual impairment is very high at $93 \%$ in this study. A study in Ethiopia reported $94 \%$ of students had blindness ${ }^{10}$, another conducted in Edinburgh, Scotland, reported blindness in $81 \%$ of students ${ }^{11}$. Our results are also consistent with a study in India in which $91.7 \%$ of the participants were classified as blind ${ }^{12}$. It is noteworthy in this situation that children who are not blind are enrolled in schools destined solely for a population with blindness.

Retinopathy of prematurity was the most frequent cause of visual impairment in this study at $36.7 \%$, and the retina was the main anatomical site affected. Other studies reported the lens as the main affected site, which in this study accounted for $20 \%$ of cases. A study from Nigeria reported that the lens was the main cause, at $30.7 \%{ }^{13}$. However, a study carried out in India found an incidence of $31.1 \%$ for the retina as the main affected site $^{9}$, and another one conducted in the Czech Republic reported a $54.2 \%$ incidence ${ }^{14}$, which was very similar to our findings $(60 \%)$. Nevertheless, both studies reported retinal dystrophies or albinism as main retinal disorders, and only $1.9 \%$ of cases were due to retinopathy of prematurity ${ }^{15}$. Studies in the Latin American Countries of Argentina, Paraguay, and Cuba, which have a similar level of development to Mexico, reported similar results to those found in the present study, with $30 \%$ of cases attributable to retinopathy of prematurity ${ }^{5,6}$.

In previous scientific articles, they reported measles as one of the main causes, ${ }^{12}$ however, the immunization implemented in Mexico since 1978 correlates with the low incidence in this study, since no outbreaks have been reported since $1996^{16}$. Therefore, the incidence of measles in childhood is very low.

Most of the participants in this study did not have ophthalmological examinations for the detection of ocular diseases and, therefore, they were not offered to undergo surgery or did not receive treatment in the early stages of their disease. In other studies reported in the literature, most patients are not offered surgery, because their disease was considered a non-surgical condition ${ }^{3}$.

Offering surgery at this stage would associate with a poor prognosis related to the time of evolution and the poor development of foveal function. This highlights the importance of an early diagnosis and treatment of eye diseases.

In Mexico, there are guidelines for the detection and treatment of retinopathy of prematurity since 2007 that highlight the need of an ophthalmologic exam, especially of the retina, in all premature newborns under 34 weeks of gestational age and/or with a birth weight lower or equal than $1,750 \mathrm{~g}$, as well as premature children with associated risk factors or with an untoward clinical evolution ${ }^{17}$. In 2013, the General Health Law was amended in order to comply with these guidelines, making a retinal exam mandatory for premature patients in the fourth week of extrauterine life ${ }^{18}$.

Consistent with literature reports, $73 \%$ of participants had a cause of blindness that could have been treated, if it had been detected in early stages. In developing countries, this finding is reported in $75 \%$ of cases ${ }^{8}$.

Two of the participants were visually impaired and not blind, so the methods for teaching and rehabilitating them could be different. One of the participants had a diagnosis of ametropia with moderate visual prognosis at the time of the study, so optical correction was indicated with eyeglasses and close monitoring for possible relocation in another type of school. It is very important to analyze a potential treatment for all children with visual impairment before enrolling them in a school for the blind.

It is difficult to obtain reliable information on the causes of visual loss in children when there is no registry for blindness. Examining children in schools for the blind can provide this information relatively easily but 
with several limitations and cannot be used to estimate specific prevalence data.

The estimated prevalence of pediatric blindness in Mexico is 0.3 in 1,000 children $^{19}$, calculated using the model proposed by Gilbert and Foster ${ }^{20}$ based on infant mortality in children under 5 years of age. Based on this prevalence, there are approximately 164 children with blindness in Queretaro, so approximately $18 \%$ of this population was enrolled in the school participating in this study.

It is important to consider that not all children with blindness have access to special education, nor are they accepted in schools for the blind. For example, those who have an additional disability, such as psychomotor developmental delay, will not be represented in this sample, as well as preschool-aged children. However, obtaining data from these population groups is difficult, since they are not enrolled in any rehabilitation program or are randomly distributed in different schools for children with psychomotor retardation.

The association among nystagmus and strabismus found in this study is expected, because the affected children have blindness; however, this study reported higher, respective prevalence rates of $43.3 \%$ and $26.7 \%$ compared to previous studies reporting $11.9 \%$ for nystagmus and 20\%-28\% for strabismus ${ }^{21-23}$.

\section{Conclusions}

Although this study had a small sample, it provides a reflection of the prevalence visual alterations in a local pediatric population, and highlights the need to implement and reinforce actions in the health system for the prevention of blindness in the pediatric population. Considering the repercussions related to health and quality of life, as well as the economic and social costs, visual examination of the pediatric population should become a priority, since $73 \%$ of the causes of blindness in this study were avoidable. The retina was the main anatomical site causing blindness and visual disability, followed by the lens. The most common diagnosis was retinopathy of prematurity, followed by cataract. This study highlights the importance of ocular examinations beginning in the first month of life.

\section{Ethical disclosures}

Protection of human and animal subjects. The authors declare that no experiments were performed on humans or animals for this study.
Confidentiality of data. The authors declare that they have followed the protocols of their work center on the publication of patient data.

Right to privacy and informed consent. The authors declare that no patient data appear in this article.

\section{References}

1. World Health Organization, Global Data on Visual Impairments 2010. Geneve: WHO; 2012. Disponible en: http://www.who.int/blindness/GLOBALDATAFINALforweb.pdf. Consultado el 22 de marzo 2018.

2. Gilbert CE, Anderton L, Dandona L, Foster A. Prevalence of visual impairment in children: a review of available data. Ophthalmic Epidemiol. 1999;6(1):73-82

3. Omolase CO, Aina AS, Omolase BO, Omolade EO. Causes of blindness and visual impairment at the school for the blind owo, Nigeria. Ann Ib Postgrad Med. 2008;6(1):49-52.

4. Zepeda-Romero LC, Barrera-de-Leon JC, Camacho-Choza C, Gonzalez Bernal C, Camarena-Garcia E, Diaz-Alatorre C, et al. Retinopathy of prematurity as a major cause of severe visual impairment and blindness in children in schools for the blind in Guadalajara City, Mexico. $\mathrm{Br} J$ Ophthalmol. 2011;95:1502-5.

5. Gilbert C, Fielder A, Gordillo L. Quinn G, Semiglia R, Visintin R, Zin A. Characteristics of Infants with severe retinopathy of prematurity in countries with low, moderate and high levels of development: implications for screening programs. Pediatrics. 2005;115(5):e518-25.

6. Muñoz B, West SK. Blindness and visual impairment in the Americas and the Caribbean. Br J Ophthalmol. 2002;86:498-504.

7. Gilbert C, Foster A, Negrel AD, Thylefors B. Childhood blindness: a new form for recording causes of visual loss in children. Bull World Health Organ. 1993;71:485-9.

8. Organización Mundial de la Salud. CIE-10. Enfermedades del ojo y anexos (HOO-H59). Cap. VII; 2016.

9. Senso de población y vivienda INEGI, información por entidad. Disponible en: http://cuentame.inegi.org.mx/monografias/informacion/queret/poblacion/default.aspx?tema $=$ me\&e $=22$

10. Kello AB, Gilbert C. Causes of severe visual impairment and blindness in schools for the blind in Ethiopia. Br J Ophthalmol. 2003;87:526-30.

11. Alagaratnam J, Sharma TK, Lim CS, Fleck BW. A survey of visual impairment in children attending the Royal Blind School, Edinburg using the WHO childhood visual impairment data base. Eye. 2002;16(5):557-61.

12. Hornby SJ, Adolph S, Gothwal VK, Gilbert CE, Dandona L, Foster A. Evaluation of children in six blind schools of Andhra Pradesh. Indian J Ophthalmol. 2000;48:195-200.

13. Ezegwu IR, Umeh RE, Ezepue UF. Causes of childhood blindness: results from school for the blind in South Eastern Nigeria. Br J Ophthalmol. 2003;87(1):20-3.

14. Kocur I, Kuchynka P, Rodny S, Barakova D, Schwartz EC. Causes of severe visual impairment and blindness in children attending schools for the visually handicapped in Czech Republic.Br J Ophthalmol. 2001; 85:1149-52.

15. Hornby SJ, Xiao Y, Gilbert CE, Foster A, Wang X, Liang X, et al. Causes of childhood blindness in the People's Republic of China: results from 1131 blind school students in 18 provinces. Br J Ophthalmol. 1999;83 (8):929-32.

16. Consejo Nacional de Vacunación. Programa de Vacunación Universal 1995-2000. México, DF: CONAVA; 1995.

17. Organización Panamericana de la Salud. Pautas para el examen, detección y tratamiento, de la retinopatía del prematuro en Latinoamérica. Disponible en: http://www.v2020la.org/docs/guias_rop_cancun_07.pdf

18. Secretaria de Salud de México. Manejo de la retinopatia del recién nacido prematuro. Lineamiento técnico. 2. . ed. 2010. ISBN-978-970-721-441-5 (citado 3 de agosto de 2015). Disponible en: http://saludmaternamedicos. blogspot.mx/2011/09/lineamiento-tecnico-manejo-de-la.html

19. Gilbert C, Awan H. Blindness in children. BMJ. 2003;327 (7418):760.

20. Foster A, Gilbert CE. Epidemiology of childhood blindness. Eye. 1992; 6:173-6.

21. Fakhoury O, Aziz A, Matonti F, Benso C, Belahda K, Denis D. [Epidemiologic and etiological characteristics of congenital cataract: study of 59 cases over 10 years] J Fr Ophtalmol. 2015;38:295-300.

22. Kim KH, Ahn K, Chung ES, Chung TY. Clinical outcomes of surgical techniques in congenital cataracts. Korean J Ophthalmol. 2008;22:87-91.

23. Zhu X, Du Y, He W, Sun T, Zhang Y, Chang R, et al. Clinical Features of Congenital and Developmental Cataract in East China: A Five-year Retrospective Review. Sci Rep. 2017;26;7(1):4254. 